\title{
'Associated life': democratic professionalism and the moral imagination.
}

\author{
Professor Paul Maharg
}

\begin{abstract}
Democratic professionalism is as much a practice as it is a constellation of values, a practice that is built around models of active and collaborative democratic change. One of the many problems inherent in democratic professionalism is that professionals may engage only in technocratic professionalism (concerned with technical self-interested practices and motivations driven by commercial profit only) instead of civic professionalism, which invests professional practice with moral meaning and with democratic value.
\end{abstract}

This chapter argues, first, that Dewey's form of educational praxis is one method by which we can encourage democratic professionalism; and that a key element of our approach should be the Deweyan concern with 'associated life' and 'associated thought', namely the cultural and social forms of professional association, and the forms and patterns of social thinking that professionals undertake in practice. Second, Dewey's concerns were central to the concerns of Scottish Enlightenment literati, and their work allows us to see problems of technicist professionalism. Third, and moving from the eighteenth century to the early twenty-first century, the internet offers us significant opportunities to engage in new forms of social and educational engagement, and particularly in online games and forms of social software. Two case studies are offered. The first describes a regulatory initiative to embody Deweyan forms of associated life, while the second describes an educational initiative that attempts to embody Dewey's value of associated thinking.

'Individuals will always be the centre and consummation of experience, but what the individual actually is in his life experience depends upon the

nature and movement of associated life'.

(Dewey LW 14, 91)

[E]xcellence can only be motivated, it cannot be

coerced.

(Stronach 2002, 138)

\section{Introduction}

As Abel demonstrates so well, the complex relationship of democracy and the politics of professionalism is highly contested within the legal profession (Abel 2003). In legal education, the relationship between democracy and professionalism has been underdeveloped, not just in theory but in educational practice as well. It should come as no surprise: both domains are historically contingent and highly contested, and there is no foundational body of theory bridging them. Mainstream undergraduate programmes will contain analyses of the place of law in democratic societies, and there are of course syllabi on professionalism, often in modules that focus on the place of the legal profession in society. In postgraduate vocational courses generally there is by contrast a focus on technical aspects of legal practice, often dealing quite narrowly with a set of regulations as they apply to technical practice - conflict of interest, confidentiality and the like. But very few undergraduate and vocational programmes, for a range of complex reasons, give a broad view of professionalism and democracy. While there is critique (see for instance Boon, Flood \& Webb, 2005; Flood, 2011) the subject, it could be said, is unregarded, and as a 
result becomes invisible to students. Nor is it sufficient to say of the constellation of values around professionalism and democracy that it can only be 'caught' within professional practice rather than learned and taught within educational programmes. If we are introducing students to legal professional and ethical values as an essential to the practice of justice in society, it might be legitimately asked of us where concomitant values appear in our programmes and methods. It could be argued that we should critique and practise versions of the values of critical professionalism in our programmes and in our educational practices.

In the literature of professionalism there is a movement to begin to analyze why and how this invisibility might have come about. In addition to the work of Larson (1977), Nelson \& Trubek (1992) and Abel (2003) on professionalism, commentators such as Pellegrino et al (1991), Dzur (2002) and above all Sullivan (2004) have shown how normative assumptions concerning the relationship of ethics and professionalism need to be re-thought, and not just with regard to the profession, but also in educational processes. Sullivan identified the importance of integrity, security and democracy to the whole professional project integrity, in terms of personal fulfilment and public recognition; security, in terms of the ever-evolving pact struck with society as regards remuneration, trust and social good; and democracy, in terms of the interface that can be developed between technical processes in society generally and the political and moral processes that underlie them. Sullivan contrasts technocratic professionalism (concerned with technical self-interested practices and motivations driven by commercial profit only) with civic professionalism, which invests professional practice with moral meaning and with democratic value.

Dzur goes further and in a helpful comparison of de Tocqueville, Dewey, Sullivan and Fischer analyzes what democratic professionalism might consist of. He defined its values over against its shadow, namely technocratic professionalism. His critique is worth quoting in detail:

If the ideal of democratic professionalism is so beneficial, then why is it losing to the technocratic model? An obvious reply is that the latter fits neatly into the rationalized procedures and needs for predictability and control found in modern economic and political organization. Further, those trained for professions currently have minimal instruction in the democratic consequences of their professional domains. Applied ethics instruction abounds, of course, and more so with every passing year. Yet the explicitly democratic values of lay participation and tasksharing discussed in this paper are rarely part of the ethics seminars required in nearly all professional training curricula.

What is interesting about Dzur's approach here, though, is the lack of what one might term pragmatic or situationist approaches to democratic professionalism within an educational context. Dzur talks here of ethics and seminars without reference to the whole stream of educational literature (stemming ironically enough from Dewey) which argues, broadly, that talk about ethics is, educationally, important but insufficient: much more needs to be done to enact ethics within educational contexts.

Just what could be done, and the place of the moral imagination in the project, is the subject of this chapter. I would like to examine some of the issues involved in dealing with moral imagination with reference to professionalism, and how we might approach the transformation of professionalism into democratic professionalism by taking the approach summarised in Figure 1: 


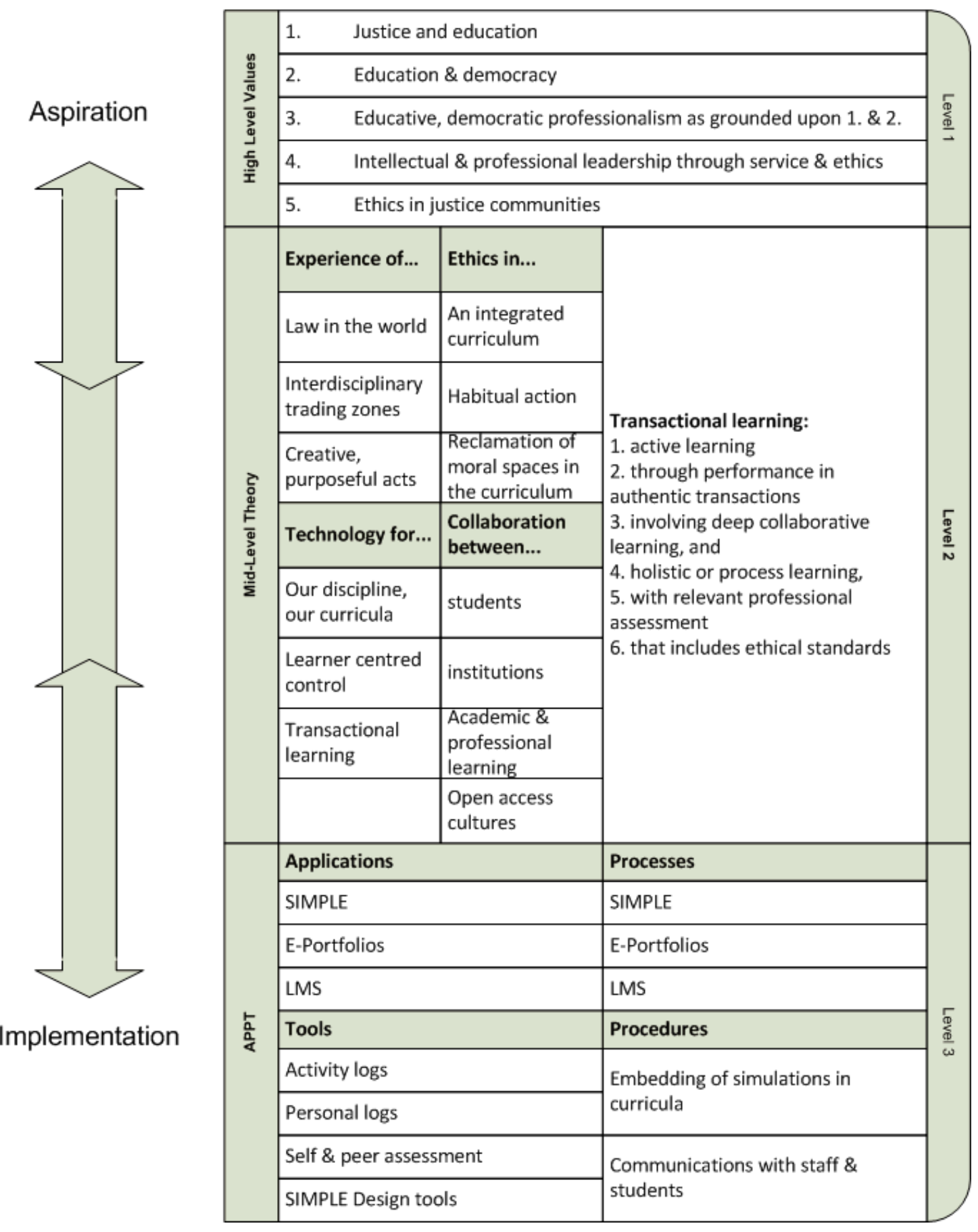

Figure 1: three levels of engagement

In this chapter we shall start with some of the values described generally at level one and work our way down; but as I hope to show, the approach is the opposite of a one-way street. Educational intention and performances are always in-tension activities, moving constantly and inescapably between the three levels of Figure 1. Aspirational values are central to almost all educational implementations. Biggs' concept of alignment is one metaphor for this (Biggs 1999). I prefer the more organic one of ecological balance, which can include aspects of values, culture and intellectual history. An ecology is never static, and it is often dependent not on the survival of what might be regarded as the higher entities, but on the survival and evolution of all entities in the ecosphere (see for example Nardi \& O'Day 1999). Choose the wrong tools or procedures at the lower end of level 3 , for instance, 
and the higher level values begin to be eroded. Ignore the values at the top end, and the tools at the lower end become the perfect instruments of a value-neutral approach to lawyering that is replete with values (often corporatist or consumerist), critiqued in so much of the literature on lawyering and legal education, particularly in the USA. A central figure in this approach is the educationalist and philosopher, John Dewey, for whom philosophy and education were almost synonymous.

\section{Deweyan educational praxis}

What is particularly appealing about Dewey's oeuvre to any analysis of moral imagination and education is the primacy he gives to experiential learning. For Dewey, learning is a social process: as he points out in Experience and Nature, the achievement of social ends cannot be reduced to prior rational self-interest alone. Human learning is inevitably drawn to the social sphere where it enacts itself and becomes more sophisticated and at the same time more open to change and improvement:

Experience is the result, the sign, and the reward of that interaction of organism and environment which, when it is carried to the full, is a transformation of interaction into participation and communication. (LW 1028$)^{1}$

Learning is experience, then, and throughout his career Dewey returned again and again to explore the nexus of learning, experience, participation and communication. In legal education experiential learning (something of a tautology for Dewey) can be the foundation for the development both of professionalism and a commitment to democratic behaviour, whether in clinic, simulation or in some other pedagogy. But as Dewey realised, commitment to democracy means embodying that commitment in the educational forms and values we use everyday within education. Ralph Sleeper makes this point well: what mattered for Dewey in all human activity, he observed, was 'the emergence of logical forms from the practice of inquiry' (Sleeper 1986, 202). Dewey's radical form of Pragmatism possessed a 'ground-map whereby [social] inequities could be identified and diagnosed, as well as a method for resolving them' (202). It is also a map for educational transformation, as radical now as it was over a century ago in Dewey's Chicago Laboratory School.

As Laurel Tanner (1997) shows in her fine study of the origins and practices of the Laboratory School, Dewey recognised the importance of collaboration and of mutuality. The School's teachers played key roles in developing Dewey's curriculum plan: their 'associated life' (see epigraph) stemmed from their 'associated thought' as professionals within an organization; and the relationship was deeply democratic. As Dewey put it,

All those who are affected by social institutions must have a share in producing and managing them. The two facts that each one is influenced in what he does and enjoys and in what he becomes by the institutions under which he lives, and that therefore he shall have, in a democracy, a voice in shaping them, are the passive and active sides of the same fact. ( $L W 11$ 217-8)

Linked with the associated life is 'associated thought' (Dewey, LW 510 ) - which as Dzur interprets it $(2002,16)$, is collaborative working, particularly the collaborative problemsolving that Dewey especially prized as a heuristic in the Laboratory School (Tanner, 83). Dewey's interest in the social context of learning was one aspect of a more general interest, among American commentators in the 1890s, in the nature and function of sympathy. J.H. Mead's theory of the self was, as he acknowledged, a theory of sympathy (Leys 1993), while Addams and William James also explored this. It is the basis of Mead's social interactionism

\footnotetext{
${ }^{1}$ All references to Dewey's work are to the standard critical edition, The Collected Works of John Dewey, edited by J.A. Boydston, and published as The Early Works, (EW), The Middle Works (MW) and The Later Works (LW).
} 
(Joas 1985, 1997), as it was for Dewey. ${ }^{2}$ As we shall see in the next section the intellectual and cultural history of associated thought, and its effects on moral imagination are grounded in Scottish Enlightenment values, as are a number of important elements of the concepts used in the debates surrounding professionalism.

\section{Moral imagination and associated thought.}

The moral imagination plays an important role in associated thought for it is critical to the sympathetic construction of the other. The concept of associated thought derives, at least in the modern period, from the Scottish Enlightenment debates concerning the nature and function of the moral sense. We can see this in the work of Adam Ferguson, Francis Hutcheson and Adam Smith, amongst others. Ferguson's view of the moral imagination was linked to the moral sense. He agreed with other literati on the Stoic position, contra Hobbes and Rousseau: civic virtues were central to society, and emanated from knowledge of duty, conscience and social position (Haakonssen 1990). ${ }^{3}$ More than most, he emphasized that individual virtue contributed to the wider social good: 'the immediate uses of moral law are choice, practice and conduct' (Ferguson 1978, 6). Ferguson therefore recommended social activism, participation in public and political life and, remarkably, the development of education in civics in schools (Hill 2006, 216; 219-20). Ferguson's view of moral cognitivism is highly social, but as with much of his thought it exists in tension. He emphasizes that social action is the result of moral agents acting on the world, and he held that, as moral agents, we act through self-discovery and self-emergence in daily practices, habits and interaction (Maharg 2007b, 107; Hill 2006, 143).

Ferguson's view of social action was grounded in the concept of Hutcheson's 'moral sense', which was not merely a philosophic and cognitive category but an aesthetic one, too. ${ }^{4}$ Hutcheson's moral sense, literally a sense, may appear to be merely a version of eighteenth century faculty psychology, but it is more subtle than that. Hutcheson held that beneficence and the perception of virtue are acts of cognition and affect primarily, but they are also, inevitably, legal and political in their nature and consequences. That they are so is promoted in society because, according to Hutcheson, all our civil institutions including legal institutions and universities, require to contribute to the virtue and self-fulfilment of all. ${ }^{5}$ This belief Hutcheson would have encountered in Stoic sources, though as Hannah Arendt pointed out, there is an earlier source in Plato. ${ }^{6}$

Contradicting Rousseau, Hutcheson defined the moral sense as a key sense for the apperception of the link between learning and virtue (Hill 2006, 199, n. 1278). The aesthetic quality is important: as Kivy points out, Hutcheson's understanding of the nature and role of

\footnotetext{
${ }^{2}$ As Dewey put it in a piece entitled 'The Ethics of Democracy', and commenting on those who would focus on individual human traits only, 'the non-social individual is an abstraction arrive at by imagining what man would be if all his human qualities were taken away' (EW 3 227-49).

${ }^{3}$ For further comment see Marshall 1984.

${ }^{4}$ I discuss this in more detail in my chapter in a forthcoming book (Maharg 2012).

${ }^{5}$ As Mautner points out, Hutcheson does not deny the importance of rights in discussions of moral positions this is clear from his treatment of jurists such as Pufendorf and Grotius. However Hutcheson does suggest, regarding these and other jurisprudential commentators, that their context is too narrow, and that the structure and operation of rights needs to be seen within a wider moral and ethical context. Mautner put this well: His complaint, one which he seems to have been the first to articulate, and which has often been heard subsequently, is directed against the tendency to identify moral theory with a theory of rights, and against the view that respect for a person's rights is the only important kind of moral consideration. (Mautner 1993, 53)

${ }^{6}$ As she put it, Plato reproached Pericles 'because he did not "make the citizen better" and because the Athenians were even worse at the end of his career than before (Gorgias, 515)' (Arendt 1958, 188).
} 
the sensus communis in aesthetic matters pre-dates Kant's treatment of 'aesthetic idea' and the fusion of aesthetic form and content; and is more subtle in his resolution of the difficulty in accounting for the source of aesthetic pleasure (Kivy 2003, 280-82). It is so partly because of Hutcheson's treatment of the imagination as the power by which the moral sense operates - to a considerable degree, it is still imaginative and aesthetic feeling that impels the moral sense. The imagination operated by ideas such as fitness - a key term for eighteenth century aesthetics and metaphysics - which included the perception of qualities in an object such as proportion, design, aspects of beauty and the like. ${ }^{7}$

It is interesting that, as Brown observes, in his early work the moral sense springs from a disinterested impulse to do good for its own sake, while in later work it becomes more social, affected by the responses from others. Later still, Hutcheson emphasizes the link between the moral sense and conscience, with the sense of judgement - ethical, moral and religious judgment - that that may entail (Brown 1994, 63-4). ${ }^{8}$ In this we can see possible origins for Smith's description and analysis of the bond between morality and accountability. As he put it (Smith 1976), '[a] moral being is an accountable being. An accountable being, as the word expresses, is a being that must give an account of its actions to some other, and that consequently must regulate them according to the good-liking of this other'. ${ }^{9}$

It is relatively easy to grasp the idea of a moral sense; but part of its problem is how imagination operates in actuality to develop it. Hutcheson's responses to his critics John Clark and Archibald Campbell on the subject describes how sympathy plays a key role (Turco 1999). The issue is, as Hutcheson, Ferguson and Smith realized, not merely one of cognition. It also involved our awareness of how the imaginative narratives (of motive, cause, event, character and the like) that we create in part out of our moral sense and sympathy can affect others. In the twentieth century Arendt pointed out how speech and narratives, much more than philosophy and political economy tracts, can engage others in a critical argument precisely because they deal in situations, in particular circumstances, and can persuade listeners and readers to come to complex moral and ethical decisions (Arendt 1958, 17588). ${ }^{10}$

For Smith, one of the problematics of sympathy was how one might be at one and the same time both inside oneself and yet the impartial spectator of whom Smith approves (Smith 1976, III.3.25). As Brown points out $(1994,70)$ Smith's philosophical voice is 'unable to achieve a complete resolution in which the sympathetic construction of the impartial spectator achieves a state of moral wholeness for the moral agent' (Brown 1994, 75). I agree with her that in Smith as in Hutcheson we see less of the calm and generous Stoic citizen and more of a 'fractured and struggling moral being' (Brown 1994, 75). It is a moral being that is familiar from the work of Ferguson, too; and not because of the difficulty of the Stoic position per se. As Hill put it, Ferguson was concerned about the new economic and moral conditions rapidly taking hold in Scotland: he 'fretted about the increasingly important role of prudential reasoning, bureaucratic rationality and centralised planning in the running of societies and, in particular, their effects upon the moral strength of nations' (Hill 2006, 11).

\footnotetext{
${ }^{7}$ Kivy points to the link between association of ideas and the perception of fitness as an aesthetic category (Kivy 2003, 184-88). See also Darling (1989) and Sheridan (2007).

${ }^{8}$ To a considerable degree, though, it is still imaginative and aesthetic feeling that impels the moral sense.. See Harrison (1995) for the link between imagination and easthetics in Smith, and evidence of Smith's debt to Hutcheson in this regard.

${ }^{9}$ Quoted in Dubnick (2010).

${ }^{10}$ See also Gottsegen (1994, 180-84).
} 
Hutcheson's central idea of the moral sense mutated in the later eighteenth and nineteenth century in the hands of Stewart and Reid into forms to which he would not have assented, but which were nevertheless influential in their own right. ${ }^{11}$ The flexible links between moral theory and lived practice advocated by Hutcheson, however, became formalised in courses in undergraduate Moral Philosophy and Ethics. The Hutchesonian legacy also lived on in a migrated form. Hutcheson's ideas on beatific moral theory were significantly influential in university and political circles in North America (Norton, 1976). John Dewey first encountered them while a student in the Department of Philosophy at the University of Vermont, and he would have been familiar with constellations of Stoic and Enlightenment thinking around the moral sense, sympathy and the association of ideas. ${ }^{12}$ While he moved well beyond them in his own philosophical and educational thinking, there were some ways in which he was, paradoxically, moving towards Hutcheson, particularly in his idea that learning is a social process. As he writes in Experience and Nature, the achievement of social ends cannot be reduced to prior rational self-interest alone (any more than it could be for Hutcheson). Human learning, including learning in morals, is inevitably drawn to the social sphere where it enacts itself within a social context, and becomes more sophisticated and at the same time more open to change and improvement:

[t] he principle of continuity of experiences means that every experience both takes up something from those which have gone before and modifies in some way the quality of those which come after. $(L W, 10,35)$

Learning, including learning in moral imagination, is also experience, then; and throughout his career Dewey returned again and again to explore the nexus of learning, lived experience and participation in imaginative action. It was for him the foundation for the development both of professional behaviour, ethical commitment and indeed the ground of democratic action for individuals and institutions. It can be so for us in legal education, whether in clinic, simulation or in any similar experiential pedagogy, where there is commitment to democratic and ethical behaviour in the everyday educational ideas, gestures, physical environment and abstract structures we surround ourselves with.

How might these Deweyan values be explored and used in legal education? The next section, the first of two case studies, is a study in regulatory change, one based not just on Deweyan concepts, but on the analysis of key Enlightenment ideas such as fitness, accountability, and learning via narrative.

\section{CASE STUDY ONE: Professional legal education and regulation in Scotland}

If the values of professionalism and the interface between moral values and professionalism are becoming an issue of key concern to educators, it is even more so for regulators of professions, and not just because of high-profile cases such as Enron in business, the recent cases of financial services fraud, or the case of Harold Shipman in medical practice.

Research is focusing on what professionalism might be, how it might be taught and learned, and how it might be measured. Papadakis et al, for instance, set out to determine if medical

\footnotetext{
${ }^{11}$ As Cairns points out $(1992,169)$, by the mid-eighteenth century natural law thinking had come to dominate the moral philosophical curriculum in the Universities of Edinburgh and Glasgow. Maharg (2012) describes some of influences of Hutcheson's thinking in the nineteenth century, as does Ward (2002).

12 For example in addition to reading the basic texts he read John Stuart Mill's analysis of Hamilton (Mill 1866). See Feuer (1958). Dewey may even have borrowed the phrase from Dugald Stewart, who analyzed the effects of 'perceptible objects' on 'associated thoughts and associated feelings' (Stewart 1854, II, 256).
} 
students who demonstrated unprofessional conduct in medical school were more likely to be disciplined by their State Board. Their study set out possible correlative factors, including gender, grade point average, Medical College Admission scores, school grades, National Board of Medical Examiner Part 1 scores and negative excerpts from evaluation forms. The study subjects were alumni graduating between 1943 and 1989. They revealed correlations between unprofessional behaviour at medical school, and practitioners who had been disciplined by their profession. As they reported,

We found that UCSF School of Medicine students who received comments regarding unprofessional behaviour were more than twice as likely to be disciplined by the Medical Board of California when they become practicing physicians than were students without such comments. The more traditional measures of medical school performance, such as grades and passing scores on national standardized tests, did not identify students who later had disciplinary problems as practicing physicians. ${ }^{13}$

What this and similar research reveals is the misalignment between professional values and educational methods and assessment processes. But it also reveals two significant issues in the educational structure of professions. First, the questions that arise in reading research findings such as this - what constitutes 'unprofessional behaviour'? Who determines that? What are the normative performance baselines for such a concept? - need answering by regulatory bodies in dialogue with other stakeholders in the profession, and with reference to research on professionalism. For example Selznick (1992) has pointed out the need for professionals to be 'genuinely other-regarding and constructively self-regarding'. Selznick goes on to characterize the 'responsible self' as being manifested in three ways: characterdefining choice, self-affirming participation, and personal statesmanship' (1992, 227). His traits of the moral self, strikingly similar to those outlined by Ferguson in his Institutes, and quoted earlier, go to the heart of the regulatory enterprise and compel us to ask searching questions: what is regulation? What is being regulated? Can regulation enforce moral conduct? ${ }^{14}$

Second, the critical literature on professionalism itself analyzes the deep structures of the term as a social construct, and this needs to be brought into educational processes, and inform the regulatory process. Stronach et al, for instance, has explored the nature of professionalism, caught between an 'economy of performance' and various 'ecologies of practice', with professionals themselves located in the 'nexus between policy, ideology and practice'. They go on to critique the 'reductive typologies and characterizations of current professionalism', and they argue for the construction of professional identities that arise from the local, situated and indeterminable nature of professional practice, and the inescapable dimensions of trust, diversity and creativity' (Stronach et al 2002, 109).

The Law Society of Scotland is an example of a regulatory body that is coming to terms with these issues of professional values. The Diploma in Legal Practice, the current primary professional programme it has regulated for over 30 years, has undergone review in a wide consultation on the future of legal education in Scotland, with proposals for a programme to be called Professional Education and Training (PEAT) 1 to replace it. Before we examine this

\footnotetext{
${ }^{13}$ Papadakis, M. et al (2004) Unprofessional behavior in medical school is associated with subsequent disciplinary action by a state medical board, Academic Medicine, 79, 244-79. See also Papadakis, M. et al (2004) Early detection and evaluation of professionalism deficiencies in medical students, Academic Medicine, 76, 1100-1106

${ }^{14}$ Ferguson's words are quoted on p. XXXX above: 'the immediate uses of moral law are choice, practice and conduct' (Ferguson 1978, 6). Selznick's work on the moral content of social theory is based firmly in Dewey's and Mead's epistemological analyses.
} 
process and its outcome, it would be helpful to describe briefly the current Diploma programme and the process of change.

\section{Context of the Diploma in Legal Practice}

In Scotland until 2011 there were a number of routes to qualification as a solicitor or advocate. It was possible to sit examinations held by the Law Society of Scotland in what were known as the 'qualifying subjects', a pass in which qualified the candidate to proceed to a postgraduate course in professional subjects, called the Diploma in Legal Practice. The commonest route to the legal profession, however, was via university study. In their undergraduate years, most students studied for their LLB degree in one of a variety of routes stretching from 2-4 years, depending on their previous experience \& pattern of study. This was followed by the postgraduate Diploma, which lasted for around seven months effectively a full academic year. All students then entered a traineeship of two years in a legal office, during which the Law Society of Scotland required them to undertake a Professional Competence Course and, during their traineeship, to undertake the Assessment of Professional Competence.

The Diploma programme consisted of eight subjects and one option - in the Glasgow Graduate School of Law (a joint graduate school between the universities of Glasgow and Strathclyde - GGSL) we added another, namely the first in the following list: ${ }^{15}$

1. Foundation Course in Professional Legal Skills

2. Civil Court Practice

3. Criminal Court Practice

4. Financial Services \& Accountancy

5. Private Client

6. Professional Ethics

7. Conveyancing

8. Practice Management

9. Either Company \& Commercial or Public Administration

In the later 1990s, and as a result of dissatisfaction from students, trainees and legal service employers, the Diploma curriculum underwent revision by the Law Society, with the result that a number of skills were identified as being crucial to legal practice, and which had been, hitherto, not sufficiently been the focus of the curriculum. The Society was keen to see the Diploma develop from what it was before, namely yet another academic course focusing on substantive and procedural law, into a programme of study where attributes, values and knowledge are integrated. The Society therefore required providers to focus on a number of professional skills areas, namely:

1. Interviewing

2. Negotiation

3. Advocacy

4. Legal Writing

5. Drafting

6. Research $^{16}$

\footnotetext{
${ }^{15}$ The GGSL was a joint graduate school between the law schools of the universities of Glasgow and Strathclyde and existed 1999-2010. In the future PEAT 1 will be hosted separately by each of the two law schools.

${ }^{16}$ For more information, see Maharg (2004b).
} 


\section{From Diploma to Professional Education and Training (PEAT) programmes}

Quite soon after this review process was concluded, however, it became clear that little real change was taking place in the Diploma. One of the many lessons learned from this first attempt at changing the Diploma curriculum was the central paradox of curriculum design and change culture: inside-school reform needs to start with outside-school reform. A second, and much more ambitious, process of change was therefore embarked upon, one that was inclusive of the undergraduate programme, the traineeship experience, practitioner Continuing Professional Development (CPD) and stakeholder views.

Early in this change process, a Working Party was tasked with drawing up a set of learning outcomes for a new Diploma. The macro-design envisaged a core consisting of professionalism statements that would define the professional standards that lay at the core of the professional legal educative process (see the Appendix to this chapter). Around that were other professional standards : 'Professional Relationships' focused largely on professional relations in the programmes and traineeships (effectively one form of Deweyan 'associated thought'), while 'Professional Communications' was sub-divided into areas such as interviewing, negotiation, advocacy, etc.

The outcomes, particularly Professionalism, were drafted with much of the research into professionalism outlined above. It was not sufficient that we outlined what skills or knowledge components were going to be the focus of PEAT 1, or how they would be taught and learned within the programme of study. We also needed to consider the moral and ethical context of the programme, and the values underpinning the skills and knowledge of the substantive curriculum. Instruction without moral context implicitly teaches our students the impoverished and value-neutral model of legal practice referred to above; and many commentators, educational as well as legal, have pointed out the dangers of this approach to skills learning. ${ }^{17}$ As Ronald Barnett has pointed out,

A higher education designed around skills is no higher education. It is the substitution of technique for insight; of strategic reason for communicative reason; and of behaviour for wisdom. ${ }^{18}$

The first value statement in the Scottish list is an attempt to find a common ground to what is otherwise incommensurable in the values of democratic commitment. Just what that commitment might entail on the PEAT 1 programme is set out in the positive indicators; and could be detailed for various future educational stages. It is not defined: the debate is left for the profession to engage in, and in the open porous nature of the statement lies both its strength and its weakness. In that debate, however, is the attempt to escape a selfreferential professionalism, the values of which are 'mostly unremarkable and unobjectionable, not least because they coincide with the commitments and objectives of lawyers' traditional professionalization project' (Webb \& Nicolson, 2005, 168). Instead, a commitment to democracy reaches out to the fundamental values of our society and one that, in its recognition of the tension in those values, rejects 'the possibility of the conventional monistic approach capturing the complexity of ethical life' (Webb \& Nicolson, 2005, 169).

\footnotetext{
${ }^{17}$ See for example Toddington (1996). The problem of course is inherent in any professional programme - see Stenhouse (1983). See also Maharg, P. (2007), particularly chapter four, "'By the end of this module...": the intimate dimensions of ethical education', pp.99-118.

${ }^{18}$ Barnett, R. (1994) The Limits of Competence: Knowledge, Higher Education and Society, Milton Keynes, Open University Press, 61
} 
The Working Party therefore needed to define the value-context within which skills would be learned..$^{19}$ At the outset, there were a number of key issues to be addressed. We refined these as the following statements:

1. Knowledge and skills must be taught critically within the value system of the profession. Values such as integrity, industry, service and duty, wisdom, compassion, accountability and responsibility, all of which underpin professional relationships and activities - these values were part of the essential context of knowledge and skills, and had to be acknowledged as such. Where there was a dissonance or clash of values, this needed to be explored honestly - indeed such dissonance formed a critically important 'learning moment' in the construction and understanding of professional values as described by Stronach et al.

2. Knowledge and skills are part of professional behaviour, and professional behaviour can never be taught in classroom activities alone. It required the presence of practitioners, and often the setting of the office or the court in order to deepen the learning process, even if such settings were proxy, eg in simulations. Even in office and court, however, the process of learning professional behaviour is not only taught overtly - it is caught in trainees' observations of practitioners at work, in conversation, and at leisure. Similarly, on the PEAT 1 programme professional behaviour is 'caught' in the interstices of the curriculum. It is in this sense that the 'hidden curriculum' and the 'null curriculum' of the Diploma are useful concepts that is to say, the unintentional lessons that students learn from a curriculum, and what is unofficially labelled as irrelevant or unimportant by its absence in a curriculum (Jackson 1968, 353; Eisner 1985). Law students learn professional behaviours by observing and imitating peers, tutors, and other role-models, not just in the classroom but in hallways, cafeterias, and elevators. As the literature suggests, the process of learning professional skills can be greatly enhanced by active engagement with professional issues in the classroom and in simulations where models of behaviour can be discussed to bring out the issues involved.

3. If we were to take experiential learning seriously then we needed to acknowledge that there is a substantial difference between teaching and learning. What a teacher teaches may not be what a student learns from a teaching event. Any approach to experiential education must start from this fundamental point. (Wolf and Turner 1989).

4. New practices on the PEAT 1 programme would require to be developed and shared among all. We were not starting a course de novo, but there needed to be change in educational practices. The relation between old and new practices made change a highly complex process. There was a considerable body of existing practice at each existing Diploma centre that needed to be taken account of in the development of skills for the future. The course directors of these centres had a body of design experience, and knowledge of their tutor base. The tutors had experience of teaching and communicating with students; and they would probably have taught with a high degree of autonomy in their classes. The Society needed to facilitate change in educational practices but also enable the shared experience within centres to thrive and develop effectively, while at the same time ensuring that models of good practice were being carried out by all providers, both new and old, and were applied with reasonable consistency across the range of different providers.

5. Quality of education: 'good, fast, cheap - choose two'. So goes the engineering saying, pointing out the common sense relationship between these qualities. The challenge for providers was to become genuinely more innovative in their design of

\footnotetext{
${ }^{19}$ Maharg was one of the Working Party, as well as a member of the Society's Education \& Training Committee.
} 
teaching and learning. The challenge for the Law Society as a regulator was to enable ways for this to come about, and to do so bearing in mind the financial costs of high-quality professional education, and the words of Stronach in the epigraph: 'excellence can only be motivated: it cannot be coerced'.

6. Student perceptions of their skills-development. It is fair to say that many students believe that they are reasonably well-skilled when they graduate, and this is true of many (though not all) of them as regards academic skills. However it is also true that the great majority of them will not have undertaken intensive skills training, or used professional resources to help them learn the professional practice of law. They needed to develop new perceptions of training and education, of legal skills, and of their own changing identities if they were to learn effectively from the PEAT 1 programme. Just as a culture change was required among teaching staff, so too it would be required among students.

If PEAT 1 really were to be a 'bridge' course, then the foundations of that bridge to professionalism were the core modules, Ethics and Standards, and Professional Communications. These modules should declare to students and others that ethics are regarded as critical to professional practice by the Society, and that effective communication is a critical part of the ethical dimension of professionality. Other professions recognise this - see for example the work of Hickson et al (1992) and others in medical education and ethics. ${ }^{20}$ It was also proof that professionalism was held as a key educational quality by the Society - and again, there was good evidence from the Working Party's research that other professions had similar perspectives. ${ }^{21}$ As regards communications outcomes, two points were borne in mind:

1. The list of learning outcomes generated by the Working Party and the Consultation was a definition of the minimum or threshold experience that students should have had on PEAT 1. In other words, students should have had the opportunity to practise every minor domain on this list at least once, and preferably twice or more, with feedback. Providers were encouraged to innovate imaginatively and go beyond the threshold skill set, ideally in the form of Bruner's spiral curriculum.

2. Because there is a difference between teaching and learning as we have said, the list was not to be regarded as prescriptive of the skill or knowledge set for a capable trainee. Students themselves were to be encouraged to develop beyond the outcomes. In this regard, providers were encouraged to use portfolio learning in order to enable students to develop not merely the skills nor the fundamental values of ethics and communications alone, but also the student's own developing sense of professionalism - the Bildungsroman of professionalism. It was suggested that the portfolio could link to an undergraduate personal development file, and the forms of work-based assessment that trainees were required to undertake as part of Peat $2 .^{22}$

\footnotetext{
${ }^{20}$ The medical educational literature is extensive. See also Frank, V. et al (2000) who explored the patient perspective, 'patients who feel ignored, deserted, or who suspect that there is a 'cover up' by the medical profession, may be more inclined to sue. Failure to understand the patient and family's perspective and devaluing their point of view have also been identified as common triggers for lawsuits.'

${ }^{21}$ See for instance in medical education, Brownell and Côté (2001); Ginsburg, S., and Stern, D. (2004); Ginsburg et al (2000); Papadakis, Loeser and Healy (2004a); Papadakis et al (2004b). See also, in the teaching profession, Breger Calabrese and Hughes (2004).

${ }^{22}$ The development of this functionality is not a trivial task. A special working party was set up under the aegis of the Society's Education \& Training Committee to develop software and educational guidelines around the use of the software by staff, students and trainees.
} 


\section{Approaches to good practice}

The development of professionalism in a course of study is never an easy task, and general guidelines were drafted for providers on the following topics:

- the ways in which the teaching environment and the available resources could be used to structure student activity

- types of teaching and learning, and how the mix of learning styles contributed to knowledge acquisition and professional development

- how tasks and transactions could be interleaved and integrated with each other

- the acquisition and development by students of the shared set of terms, external representations that provide a common ground for communication and shared understanding between trainees and training firms, and between client and lawyer

There is extensive literature on this in medical education. In a series of experiments on the role of biomedical knowledge in clinical reasoning, for instance, Boshuizen and Schmidt (1992) have shown that experts acquire a robust knowledge base that integrates situated and general knowledge. Knowledge integration is an active process that involves articulating a global framework (the biomedical knowledge), reflecting on situated experiences (individual cases as they are encountered), and actively making connections between situated knowledge and the global framework.

This is also true of the legal domain. A lawyer in private practice will see something in the order of many thousands of cases in a working life. Through the experience of casework, she gains an extensive stock of what might be termed mental schemas and performance knowledge. Solicitors know this implicitly. When presented with a set of facts within their area of practice they are able quite quickly to invoke a schema and can test this initial schema against the evidence. Lesgold suggests that, in the process of becoming an expert, a trainee acquires fragments of automatized procedure that gradually become integrated into extended sequences that guide performance (Lesgold et al 1989). These sequences can be formed quite slowly from practice through the composition of fragments of activity, but the process can be made much more efficient if students are taught the procedures explicitly, as a list of steps towards problem identification and solution, and taught also to begin the process of case pattern recognition. These two forms of learning can bring trainees to a practical knowledge of a transaction much more efficiently if learning is carried out via simulation and transaction. In this respect what is true of biomedicine and radiology and many other professional domains is equally true of legal practice. And as Stronach and Selznick have pointed out, the ability and the freedom that professionals require in order to make the link between local and global is a critical function of professionalism. The practice of this function should begin in the domain of the academy, where its education in the moral imagination can be constructed.

What are the best ways to bring this about? There is no one royal road, and there is much literature about which methods are effective for which skills and in which teaching environments and stages of learning. ${ }^{23}$ Whatever method is used, it ought to be highly experiential and include elements such as role-plays, case studies, simulations, structured interviews, prompted recall, detailed analysis of achievements and performance problems in skill practice and the like.

\footnotetext{
${ }^{23}$ See for example Taverner et al (2000), and Eaton and Cottrell (1999)
} 
Great benefit can be derived from intensive coaching sessions at any stage in PEAT 1, where such sessions focus on feedback and review. It is also the case that development in professionalism is greatly enhanced if skills are embedded across the curriculum in realistic transactions. Much of the medical literature on clinical skills emphasises the importance of immediate feedback, of opportunities for practice following review, and of practice within different contexts (Kneebone et al 2002). Local course providers are therefore best placed to know where to embed skills within their courses, given their knowledge of their tutors, and other conditions pertaining to the course. However there is always a tension between local innovation and standards across the jurisdiction and across jurisdictions. ${ }^{24}$ As stated above, the problem can be resolved if jurisdiction-wide standards exist as threshold or minimum standards, and best practice is shared collaboratively among providers.

Above all, we need to return to the Deweyan value of professional life as associated life, and embed that within our teaching and learning. If the discussion in the first few sections of this chapter have been at the aspirational level one of Figure 1, the boxes at level two describe examples of the mid-level theory by which this can be achieved, and in particular the relations that need to be strengthened between students (where learning, trust and responsibility are built in collaborative activities), between institutions in the market, and between academic learning and professional learning. Given the role that any regulatory body plays in setting not just rules and benchmarks but tone, culture and relationships, it is therefore essential that key professional concepts such as fitness and accountability are defined, not in terms of the narrow technicism of policy-audit culture, but in terms of trust, openness,

In its recognition of this, and in its attempt to view legal education as a democratic process, one where associated life is of the essence in the creation of educational values, the Law Society has encouraged a unique experiment. A number of providers came together to plan collaborative inquiry and resource design. Current providers of the Diploma met informally with the Society in 2009 to examine how resources, methods and approaches to professional learning could be licensed as Open Educational Resources (OER), to determine best approaches to the use of technology, the development of ethical learning, and consider many other components of learning in associated lives. To what extent the initiative thrives depends much on the relations between providers, of course, and this will take time; but it is significant that the regulator has encouraged its existence and dynamic.

\section{Associated thought and social software}

So far we have been discussing pedagogical approaches only to the development of democratic professionalism. But - and bearing in mind Figure 1 above - let us take this down to a further level of granularity - to applications, approaches to learning in detail. Can technology play a role in enhancing democratic professionalism? If so, how might it do so, and should this be part of the regulatory project?

Recall the use of the moral imagination to develop the moral sense in the work of Hutcheson and Ferguson; and the link between associated thought and associated life, and how this was, as Tanner observed, essential to Dewey's creative problem-solving method in the Laboratory School. What Dewey created, and for both students and teachers, was what

\footnotetext{
${ }^{24}$ In a wider context this is precisely what a number of bodies in medical education are setting out to explore and improve. The work of the Institute for International Medical Education is crucial in this regard (www.iime.org). See for instance Schwartz and Wojtczak (2002); World Federation For Medical Education Task Force (2000); and World Health Organization/Education Commission For Foreign Medical Graduates (1995).
} 
James Paul Gee in recent years has called 'affinity spaces'. These are informal learning spaces where inter alia, common endeavour is primary, where novices and masters share common space, where intensive and extensive knowledge are encouraged, as well as both individual and distributed knowledge. Gee goes on to define this in more detail (Gee, 2004, 83-89) using the examples of video games. Many more studies attest to this quality of game genre - the research of Nick Yee, for example, or Constance Steinkuhler, or the research of Henry Jenkins. Taylor (2006) in her fine study of the userbase of Sony's EverQuest notes the plethora of sites associated with such games, describing them as 'a kind of "collective intelligence", an idea Henry Jenkins (2002) picks up from Pierre Levy's (1997) work on the reconfigurations occurring in contemporary society around technology and knowledge.' (Taylor, 81).

Video games and social software are examples of such affinity spaces. Facebook can of course be used for purely commercial purposes (and it goes without saying that video games themselves are hugely commercial undertakings); but like in-world texting, simulations, blogs, tweets, wikis and many other new genres of textual production in the social software revolution, they are exemplars of how Deweyan 'associated thought' can be combined with new technologies to bring about a significant shift in method and content of professional learning. What are the lineaments of this transformation for legal education in particular? They are characterised by the Level two categories of Figure 1, particularly the four boxes to the left, under the headings Experience, Ethics, Technology \& Collaboration (Maharg 2007). All four concepts (which of course express value-laden approaches to legal education) can be significantly enabled and enhanced by the use of appropriate technology, allied to educational, moral and ethical theory on Level one, and when embedded in applications such as those outlined at Level three.

In the next section I shall briefly outline how this might come about in one particular application, namely simulation. In the process of examining how such an approach works in practice we shall see how the moral imagination works in detail at this level of implementation, and how it can be enabled by the mid-level theory at level 2 .

\section{CASE STUDY 2: Professionalism and SIMPLE - associated thought in action}

This case study is a curriculum-wide implementation of simulation activities within the Diploma in Legal Practice. It involves learning face-to-face using conventional print resources, and also involves online digital resources. While the use of the web to simulate a professional environment is nothing new in itself, our implementation of it and on this scale is fairly unique. In addition, the design and use of the online learning environment has led to the re-design of face-to-face interventions, derived from other disciplines, which are unusual in legal education. Accompanying the implementation is a developing body of theory, called transactional learning (Maharg, 2007b, level 2 in Figure 1 above), which aims to describe and analyse forms of learning based upon all professional interactions, and which is relevant to both undergraduate and postgraduate courses. To do all this, we developed a simulation engine, called SIMPLE, which would enable forms of Deweyan education to be enacted within a regulatory structure - one where forms of professional learning could also, conceivably, be enacted, via 'associated thought', as forms of democratic professionalism. ${ }^{25}$

\footnotetext{
${ }^{25}$ For more information on SIMPLE as an application, see http://simplecommunity.org.
} 


\section{SIMulated Professional Learning Environment (SIMPLE)}

The simulation environment has two primary software outputs, in the form of the SIMPLE platform and SIMPLE tools, collectively known as the SIMulated Professional Learning Environment, or SIMPLE. Both products are finished to beta user stage. Each of these products is aimed at different areas of the teaching eco-system: the platform is targeted towards students \& staff, and is there to provide the day-to-day systems for engaging with and managing simulations. The tools, on the other hand, are targeted towards academic or professional educators, and allow them to design professional simulations and manage all of the resources that are required to provide an engaging learning experience. Both opensource products are available to the FE and HE communities free at point of use at http://simplecommunity.org, with appropriate open-source licence structures in place.

The SIMPLE platform is web-based, allowing access from anywhere in the world where staff and students have an internet connection. This allows for flexibility in the student learning environment as well as flexible options for staff management of student simulations (enabling more efficient multi-tasking in administration and learner support). We have made plans for extensive further development of both tools and platform.

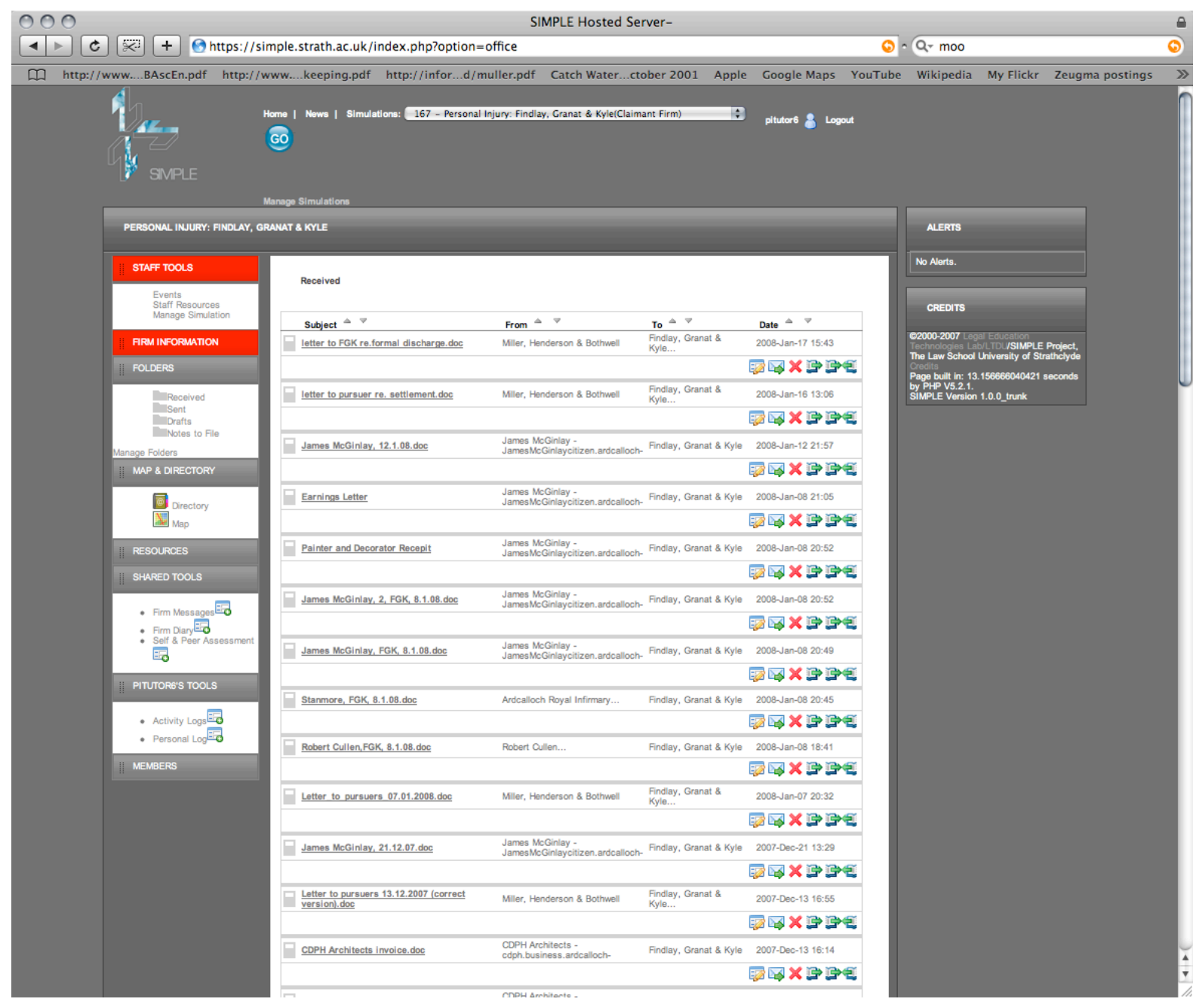

Figure 2: SIMPLE student environment

What do users do with the environment? Figure 2 is an example of the environment, seen from a tutor point of view. Staff see what students see, but with added functionality (staff would click on Staff Tools, in left-hand column to access staff-specific communication tools 
and information). Students use the environment as a professional working environment. They can receive, send and store documents, graphics, video and other file formats by uploading them to the environment. They can communicate with real or fictitious persons and institutions, and receive feedback on their work in-role. They have access to any resources that staff may wish to make available to them; they can share tools and resources. They have access to a map of a fictional town and a directory (see figure 4 below). Using the environment, students can build up the correspondence and drafts of an entire transaction, and either use the environment as a single student, or as part of a collaborative grouping.

It is difficult to describe briefly the scale of the simulation activities undertaken by students in this programme-wide simulation. For background information and further comment see Maharg (2004a), Maharg (2006), Barton \& Westwood (2006), Barton \& Maharg (2007), Maharg (2007) and Maharg \& Owen (2007). Currently at Strathclyde, students on the Diploma are formed into groups of four at the start of the academic year, each one being a simulated law firm. Sited on the south bank of the Clyde, the town acts as a complex simulation of the reality that surrounds actual legal transactions. For example in the Personal Injury Negotiation Transaction (PI), the firms act for clients, either the injured claimant or as the insurance company's solicitors, in a personal injury negotiation that lasts almost a full semester (12 weeks in total). In order to negotiate the case they need to engage in fact-finding by contacting characters and institutions within the virtual community, and pooling the information they obtain. They then need to carry out legal research on issues such as liability and quantum; set out their negotiation strategy and perform the negotiation, either by email or through a face-to-face meeting. Discussion forums for both sides support students in the complex process of carrying out this legal transaction - a Visiting Professor who is a PI solicitor is on both forums answered student queries and provided information. Postgraduate students, trainees and newly-qualified solicitors are trained to answer emails in the guise of any one of around 12 different fictional characters, and to give the appropriate information to students. They are supported by an online forum where the PI practitioner is present (author of the scenario and many resources). If they wish, students can meet as a firm with either this tutor or another negotiation tutor to discuss strategy and performance before they negotiate with the other side. This meeting is in effect a form of small-group, salon learning. It is voluntary: there are no face-to-face interventions at all, apart from an introductory and general feedback lecture (students can also, if they wish, obtain feedback on performance from file assessors at the end of the project).

This is only one of a number of simulations that use the SIMPLE environment. There are at least another six transactions on the programme. Nor is this form of learning applicable to legal professional programmes only. It has been used successfully in undergraduate law programmes at Warwick, Northumbria and Glamorgan University Law Schools; in postgraduate Masters programmes and vocational programmes. It is not jurisdictionallyspecific: it is currently being used by the Law Workshop of the Australian National University, and the University of New Hampshire Law School in the US. It has also been used successfully, in the initial JISC/UKCLE SIMPLE project, in postgraduate Architecture and undergraduate Management Science modules.

\section{Associated thought and simulation}

What is the point of this form of learning, and what part does the moral imagination play in its implementation? On a surface level, it simulates the reality of actual transactions. Note that the aim is not the replication of reality, which would be an impossibility, but simulation 
of aspects of it. This allows staff to focus on the transactional elements that students may learn - in the PI transaction, for instance, these included problem-identification and solving, the integration of different bodies of substantive legal knowledge (Delict [including liability and quantum], Tax, Welfare Law), the skills of negotiation formation within the transaction, specific forms of letter-writing, and time management of the transaction, negotiation performance, and client-centred lawyering.

Secondly, it also allows staff to create open-field transactions (such as the PI transaction) which are in effect powerful problem-based learning environments; and bounded-field transactions (such as Conveyancing, where we supply students with template documents, and the transaction is much more linear and bounded by custom and statute) - see Barton \& Maharg (2007) for more information on this, and the table below for more detail of the distinction we make.

Thirdly, it allows staff to create environments that are both zones for learning and assessment where the environments are powerful learning and testing grounds for contested value-constellations such as professionalism. Such values, as we have seen from research into the forms of education that best fit cultures of professional activity, do not fit easily into the structures of academic assessment (Stern \& Papadakis 2006). Above all, this approach avoids the damaging separation of learning from assessment that often occurs in conventional academic learning.

Fourthly, in examining the work of professionals it is clear that real professional life is about integration of knowledge into contexts that are changing continuously. That knowledge becomes valuable when it is contextualised in the narratives of professional experience. There is a considerable difference in emphasis in the notion and techniques required for professional development as compared to a technical approach to training. Professional education requires judgement rather than simple answers. This has been well articulated by Bevis \& Watson (1990), who compared a technical model against a professional model for clinical nurse education (see Table 1). The language of their comparison is similar to that of Dzur, and is close to the antinomies of Stronach et al, and to the anxieties about the nature of professional society that go back to Ferguson and Scottish Enlightenment discourse. We would argue that approaches such as SIMPLE simulations allow us shift educational practice much more to the professional end of the spectrum than to the technical end.

\begin{tabular}{|l|l|}
\hline \multicolumn{1}{|c|}{ Technical Model } & \multicolumn{1}{|c|}{ Professional Model } \\
\hline $\begin{array}{l}\text { The only learning worth evaluating can } \\
\text { be seen as behavioural changes. }\end{array}$ & $\begin{array}{l}\text { Worthwhile learning is often personal, } \\
\text { obscure and private. Only some learning } \\
\text { appears as behavioural changes. }\end{array}$ \\
\hline $\begin{array}{l}\text { Everything that exists, exists in some } \\
\text { quantity, and therefore can be counted } \\
\text { and measured. }\end{array}$ & $\begin{array}{l}\text { Many things that exist are note externally } \\
\text { verifiable. }\end{array}$ \\
\hline $\begin{array}{l}\text { The teacher-selected goals are the } \\
\text { important ones, therefore the evaluated } \\
\text { ones. Both teacher and student selected } \\
\text { Important, therefore the evaluates ones }\end{array}$ & $\begin{array}{l}\text { Both teacher and student selected goals are } \\
\text { important, as is learning attained without } \\
\text { goals. }\end{array}$ \\
\hline $\begin{array}{l}\text { Comparing behaviours to some } \\
\text { objectively held criteria or comparing to }\end{array}$ & $\begin{array}{l}\text { Educative learning cannot be rated on a } \\
\text { scale. Most learning cannot be compared }\end{array}$ \\
\hline
\end{tabular}




\begin{tabular}{|l|l|}
\hline $\begin{array}{l}\text { the progress of other students } \\
\text { determines how well something is } \\
\text { learned. }\end{array}$ & $\begin{array}{l}\text { either to some "objectively" conceived } \\
\text { criteria or to the progress of other } \\
\text { students. }\end{array}$ \\
\hline $\begin{array}{l}\text { The teacher-student relationship is } \\
\text { hierarchical and the teachers assess } \\
\text { students by how well they have met } \\
\text { specific objectives. }\end{array}$ & $\begin{array}{l}\text { The teacher-student relationship is } \\
\text { egalitarian. Learning requires a process of } \\
\text { trusting grades to exploration among } \\
\text { expert and novice learners and thrives on } \\
\text { constructive criticism. }\end{array}$ \\
\hline $\begin{array}{l}\text { The quality of rigour of a course can be } \\
\text { determined by how well it helps its } \\
\text { students meet the discipline } \\
\text { requirements as reflected by test scores, } \\
\text { attainment of behavioural objectives, } \\
\text { and accreditation requirements, since } \\
\text { these reflect the agreed-upon discipline } \\
\text { content. }\end{array}$ & $\begin{array}{l}\text { The quality of rigour of a course can be } \\
\text { determined by how well it helps students } \\
\text { collect paradigm experiences, develop } \\
\text { insights, see patterns, find meanings in } \\
\text { ideas and experiences, explore creative } \\
\text { modes of enquiry, examine assumptions, } \\
\text { form values and ethics in keeping with the } \\
\text { moral ideal of the caring scholar-clinician, } \\
\text { respond to social needs, live fully and } \\
\text { advance the profession. }\end{array}$ \\
\hline
\end{tabular}

Table 1: Technical and professional models (Bevis \& Watson, 1990, cited Maharg \& Owen, 2007)

How does simulation manage to do this? Put simply, it allows for a creative space, a middle domain of playful activity where the moral imagination is, in a Hutchesonian sense, encouraged to play. Students play roles, have the space to take up traits and characters that are not (yet) disciplined by the Weberian cage of professional practice reality, and can develop the play of imaginative sympathy, amongst other emotions, within their learning and their work.

Or not. For there is a body of work carried out by Barton \& Westwood that analyses how, in terms of learning and trust, the collaborative relationship is enacted in the simulation environment, how the ecology of that environment can shape student learning, and how students themselves shape it (Barton \& Westwood, 2006; 2011). Analyzing individual reflective reports that GGSL students wrote on their experience of working in firms, they drew up a matrix the axes of which were composed of learning and trust, with student firms plotted into one of four quadrants - high learning, high trust ('Learning Communities'); high learning, low trust ('Legal Eagles'); low learning, high trust ('Friendly Societies'), and low learning, low trust ('Dysfunctional' firms). ${ }^{26}$ The traits of the quadrants are illustrated in Figure 3.

\footnotetext{
${ }^{26}$ For examples of dissonant behaviour and problematic learning, see chapter seven, Maharg (2007b).
} 
Type 2: Legal Eagles

\section{Low Trust High Learning}

\section{Culture}

Suspicious, blame, independence, me first, team second

Task

Task focused: debate about details, my way; high engagement, exhausting

\section{Relationships}

Insular, abrasive, reluctant, limited

listening, suspicious

Work styles

Inflexible, rigid, majority, one-upmanship

\section{Type 1: Learning Community}

High Trust High Learning

Culture

Inclusive, fair, interdependence, team first, win-win

Task

Task focussed: our way; high engagement

to get things done, good communications

Relationships

Open, value each other, mutually

supportive, honest, shared responsibility,

respect

Work styles

Flexible, adaptive, learn from mistakes, consensus, responsive, resilient

\section{Type 3: Friendly Societies}

\section{High Trust Low Learning}

Culture

Inclusive, cosy, dependence, friends first, firm second

Task

Not task focussed; low engagement

Relationships

Like minded, sociable, nice, supportive

Work styles

Superficial, majority, avoid conflict

\section{Work styles}

Inflexible, superficial, dictatorial, rigid

Figure 3: Learning/Trust matrix (Barton \& Westwood, 2006)

According to their analyses the student firms achieved most in terms of academic and professional practice when they were in the Learning Community quadrant; but the first study in 2003/4 revealed a relatively high proportion of problematic traits in the formation of group dynamics, the emotional resilience of groupwork, and many other issues (see Table 3). Clearly, GGSL staff wanted as many students as possible to be in the Learning Community. In our view, and given our concept of Deweyan civic professionalism as well as our sense of the role of sympathy and feeling in collaborative work, this was where not only the most significant achievement took place, but where students learned best the ideals of a democratic professionalism. Correspondingly, we wanted Legal Eagles to be less suspicious with each other, more trusting; the Friendly Societies to be less friendly and more taskfocused, and the Dysfunctional firms to give more time to the intra-firm relationship itself, and seek help where required.

As a result, the GGSL team implemented a number of changes to the context of the firm environment on the programme. One of the changes was the development of a partnership contract amongst the firm members. Early in the programme the contract was drawn up on a template but the firms were asked to choose at least four values from a total of 31 that they would espouse in their workings with each other in the firm, and to insert these in the 
document. The document was then executed formally and witnessed by their Practice Manager, a member of staff. The values chosen by firms were tracked by staff. The most popular was reliability, with work-life balance second, and integrity and quality the third. What was interesting, however was the next most popular constellation: democracy, happiness, challenge and excellence, particularly when balanced against the values that were unused by any agreement, namely change, competition, freedom, friendships, independence, leadership, privacy and status (Barton \& Westwood, 2011, XXX). When given the choice, students chose what must surely be regarded as a more Hutchesonian constellation of values.

The partnership agreement, formed and executed during the initial Foundation Course of the Diploma, was used in subsequent sessions with Practice Managers (staff who had been given special training to be coaches, rather than tutors, to the student firms). Students and Practice Managers found it a helpful document because it clarified the commitment the firm's members had made to themselves and to each other. It also functioned, in Gee's terms, as part of the 'affinity space', and as such, contributed to the play of the aesthetic and the moral imagination precisely because it was part role-play, part reality, a mesocosmic area where learning was enhanced precisely because it took place neither in one zone nor the other entirely. In this sense the whole approach of the simulated firm environment, with its values chosen in part by students, replicates the situations of players in online games who choose their character - dwarf, elf, healer, warrior, for instance. The latest games are more sophisticated. In The Secret World, for example, players are not speciesspecific: they are given the choice of seven active and seven passive abilities, and reorganize these when they wish. As has often been observed, these games are powerful tools for imaginative play (de Freitas \& Maharg, 2011; Gee, 2004; Juul, 2005; Taylor, 2006).

The partnership agreement and other tools also helped students to focus on the local as the ground of professional value - a process that is identified in at least some of the literature on professionalism as an important influence upon the development of ethical practice. Discussing the whole process by which the ABA had developed its Model Rules for Professional Conduct, for instance, Schneyer argued against earlier critical theories about the provenance and signficance of professional ethics codes, and for a view of the Model Rules as an instance of de facto law-making by a private group. He constructed what he termed 'professionalism-in-fact' - a matrix of common themes by which lawyers thought about the field of legal ethics - and sited this in the diversity and pluralism of lawyers' practices, arguing that the roots of lawyers' ethical preoccupations could be found in the circumstances of their particular practices.

The results of the changes, charted in 2005/6 (Table 3 below), showed the significant improvement in student achievement. Compared against 2003/4, the results of 2005/6 showed fewer Legal Eagle and Friendly Society types of firms, and a significant reduction in the number of Dysfunctional firms and a corresponding increase in the number of Learning Community firms. It is significant that the results of $2004 / 5$, the year when the interventions (including the partnership agreement) were being planned, broadly replicated the results of the previous year in type 1 and 4 firms. Since then, the 2005/6 results have been maintained.

\begin{tabular}{|l|l|l|l|}
\hline & $\begin{array}{l}2003 / 04 \\
(N=51 \text { firms })\end{array}$ & $\begin{array}{l}2004 / 05 \\
(N=64 \text { firms) }\end{array}$ & $\begin{array}{l}2005 / 06 \\
(N=66 \text { firms) }\end{array}$ \\
\hline $\begin{array}{l}\text { Type } 1 \\
\text { Learning }\end{array}$ & $41 \%$ & $42 \%$ & $56 \%$ \\
\hline
\end{tabular}




\begin{tabular}{|l|l|l|l|}
\hline Community & & & \\
\hline $\begin{array}{l}\text { Type 2 } \\
\text { Legal Eagles }\end{array}$ & $27 \%$ & $14 \%$ & $18 \%$ \\
\hline $\begin{array}{l}\text { Type 3 } \\
\text { Friendly Society }\end{array}$ & $20 \%$ & $31 \%$ & $18 \%$ \\
\hline $\begin{array}{l}\text { Type 4 } \\
\text { Dysfunctional }\end{array}$ & $12 \%$ & $13 \%$ & $8 \%$ \\
\hline
\end{tabular}

Table 2: Comparison of firm characteristics (adapted, Barton \& Westwood, 2011, XXX).

\section{Conclusion}

In this chapter I have argued for situated forms of educational praxis as one way in which we can exercise the play of imagination, and direct it towards some of the critical debates about professionalism in our society. It might be thought that professionalism is too narrow a concept for the expansive values of Hutcheson, Dewey and others I have cited in this chapter; and it is certainly the case that much of the literature is sited in variants of professional technicism. But I would argue that as the ground of the professional classes, it requires recuperation and renewal, along the lines set out in this chapter. The alternative, as Dzur and others point out, is the triumph of narrow technocratic definitions of the concept by those with powerful interests to affect legal education, such as regulators and policymakers.

As we have seen, the debate about an expansive version of professionalism is nothing new. It only appears new because we have forgotten the sense of the term's larger cultural, social and philosophical context - a context that we can appreciate in the discourse of Enlightenment critiques of social theory and praxis, where imagination, through aesthetic activity in everyday life, impels the moral sense.

In the forms of situated learning described above students learn much more than the mere mechanics of professional practice. They also learn about their own developing associative life in a profession. The immersive groupwork of the virtual firm in SIMPLE becomes a microcosm, a sandbox for working practices, habits and attitudes that can function as a critique of legal practice. The affinity space of SIMPLE is a profound example of the use of technology as a form of education in the cause of democratic professionalism, advocated by Dewey, practised in his Laboratory School, and throughout his work. It is also an educational initiative that attempts to go beyond text-focused heuristics by providing collaborative, learning spaces that enable students to explore and engage in imaginative ways with identity, fitness, responsibility, decision-making, ethics and many other concepts vital to their learning of what it is to be fully professional.

\section{REFERENCES}

Abel, R. 2003. English Lawyers Between Market and State. The Politics of Professionalism. London: OUP.

Arendt, H. 1958. The Human Condition. Chicago: University of Chicago Press.

Barton, K. and Maharg, P. 2007. Simulations in the wild: interdisciplinary research, design and implementation, in Games and Simulations in Online Learning, edited by $\mathrm{C}$.

Aldrich, D. Gibson, M. Prensky. Hershey, PENN: Idea Group Ltd, 115-148.

Barton, K. and Westwood, F. 2006. From student to trainee practitioner - a study of team working as a learning experience, Web Journal of Current Legal Issues, [Online] 
special issue on Legal Education, edited by M. Spencer. Available at:

http://webjcli.ncl.ac.uk/2006/issue3/barton-westwood3.html [Accessed on: 12.4.11]

Bevis, E.O. and Watson, J. 1990. Towards a Caring Curriculum: A New Pedagogy for Nursing. New York: National League for Nursing.

Biggs, J. 1999. What the student does: teaching for enhanced learning. Higher Education Research \& Development, 18(1), 57-75.

Boon, A., Flood, J., Webb, J. 2005. Postmodern professions? The fragmentation of legal education and the legal profession. Journal of Law and Society, 32(3), 473-92.

Boshuizen, H. P. A. and Schmidt, H. G. 1992. On the role of biomedical knowledge in clinical reasoning by experts, intermediates and novices. Cognitive Science, 16, 153-184.

Breger, M.L., Calabrese, G.M. and Hughes, T.A. 2004. Teaching professionalism in context: insights from students, clients, adversaries and judges. South Carolina Law Review, 55, 303-47.

Brown, V. 1994. Adam Smith's Discourse: Canonicity, Commerce and Conscience. London and New York: Routledge.

Brownell, A.K.W. and Côté, L. 2001. Senior residents' views on the meaning of professionalism, and how they learn about it. Academic Medicine, 76(7), 734-7.

Cairns, J. 1992. The influence of Smith's jurisprudence on legal education in Scotland, in Adam Smith Reviewed, edited by P. Jones, A.S. Skinner. Edinburgh: Edinburgh University Press.

de Freitas, S., Maharg, P. 2011. Digital games and learning: modelling learning experiences in the digital age, in de Freitas, S., Maharg, P. (eds) Digital Games and Learning, London: Continuum Press.

Dewey, J. 1969-72. The Early Works of John Dewey, 1882-1898, edited by J.A. Boydston, Carbondale, IL: Southern Illinois University Press.

Dewey, J. 1976-83. The Middle Works, 1899-1924, ed. J.A. Boydston Carbondale, IL: Southern Illinois University Press.

Dewey, J. 1981. The Later Works, 1925-1953, ed. J.A. Boydston Carbondale, IL: Southern Illinois University Press.

Darling, J. 1989. The moral teaching of Francis Hutcheson. Journal for Eighteenth-Century Studies, 12(2), 165-74.

Dubnick, M.J. 2010. 'A moral being is an accountable being': Adam Smith and the ethical foundations of accountable governance. Paper presented at the 68th Annual Meeting of the Midwest Political Science Association, The Palmer House, Chicago IL, May 22-25, 2010. Available at:

http://mjdubnick.dubnick.net/papersrw/2010/mwsmith2010.pdf [Accessed on: 12.4.11].

Dzur, A.W. (2002) Civic Participation in Professional Domains, Paper delivered at the Annual Meeting of the American Political Science Association, Boston, August-Sept 2002, [Online ]. Available at:

http://muse.jhu.edu/login?uri=/journals/good_society/v013/13.1dzur01.html [Accessed on: 12.4.11].

Eaton, D.M. and Cottrell, D. 1999. Structured teaching methods enhance skill acquisition but not problem-solving abilities: an evaluation of the "silent run through"'. Medical Education, 33(1), 19-23.

Eisner, E.W. 1985. The Educational Imagination: On the Design and Evaluation of School Programs. New York: Macmillan.

Ferguson, A. 1978. Institutes of Moral Philosophy. [1769] New York: Garland Publishing Company.

Feuer, L.S. 1958. John Dewey's reading at college. Journal of the History of Ideas, 19(3), 41521. 
Flood, J. 2011. Legal Education in the Global Context. Challenges from Globalization, Technology and changes in Government Regulation. Report for the Legal Services Board.

Frank, V. et al 2000. A survey of physician training programmes and communication skills for malpractice prevention. Journal of Law, Medicine and Ethics, 3.

Ginsburg, S., Regehr, G., Hatala, R., McNaughton, N., Frohna, A., Hodges, B., Lingard, L. and Stern, D. 2000. Context, conflict, and resolution: a new conceptual framework for evaluating professionalism. Academic Medicine, 75(10 Supplement), 56-11.

Ginsburg, S., and Stern, D. (2004) The professionalism movement: behaviours are the key to progress, The American Journal of Bioethics, 4(2), 1-14.

Gottsegen, M.G. 1994. The Political Thought of Hannah Arendt. New York: State University of New York Press.

Haakonssen, K. 1990. Natural law and moral realism: the Scottish synthesis, in M.A. Stewart, ed, Studies in the Philosophy of the Scottish Enlightenment. Oxford: Clarendon Press.

Harrison, J.R. 1995. Imagination and aesthetics in Adam Smith's epistemology and moral philosophy. Contributions to Political Edonomy, 14, 91-112.

Hickson, G.B. et al. 1992. Factors that prompted families to file medical malpractice claims following perinatal injuries. Journal of the American Medical Association, 267, 135963.

Hill, L. 2006. The Passionate Society. The Social, Political and Moral Thought of Adam Ferguson. Dordrecht, Netherlands: Springer.

Jackson, P. 1968. Life in Classrooms. New York: Holt, Rinehart, and Winston.

Jenkins, H. 2006. Convergence Culture. Where Old and New Media Collide. New York \& London: New York University Press.

Joas, H. 1985. G.H. Mead. A Contemporary Re-Examination of His Thought, translated by R. Meyer. Oxford: Polity Press.

Joas, H. 1997. George Herbert Mead and the renaissance of American pragmatism, in C. Camic, ed., Reclaiming the Sociological Classics. The State of the Scholarship. Malden, MASS: Wiley-Blackwell, 262-81.

Juul, J. 2005. Half-Real. Video Games Between Real Rules and Fictional Worlds. Cambridge, MASS: MIT Press.

Kivy, P. 2003. The Seventh Sense. Francis Hutcheson and Eighteenth-Century British Aesthetics, second edition, Oxford: Clarendon Press.

Kneebone, R. et al 2002. An innovative model for teaching and learning clinical procedures. Medical Education, 36, 7, 628-34.

Larson, M. 1977. The Rise of Professionalism: A Sociological Analysis, London, University of California Press.

Lesgold, A., Glaser, R., Rubinson, H., Klopfer, D., Feltovich, P. and Wang, Y. 1989. Expertise in a complex skill: diagnosing X-ray pictures. In M. Chi, R. Glaser and M. Farr, editors, The Nature of Expertise. Hillsdale, New Jersey: Lawrence Erlbaum.

Leys, R. 1993. Mead's voices: imitation as foundation, or, the struggle against mimesis. Critical Inquiry, 19(2), 277-307.

Maharg, P. 2004a. Virtual communities on the web: transactional learning and teaching, in Aan Het Werk met ICT in het Academisch Onderwijs, edited by A. Vedder, Nijmegen: Wolf Legal Publishers, 75-93.

Maharg, P. 2004b. Professional legal education in Scotland, Georgia University State Law Review, 20(Summer), 947-77.

Maharg, P. 2006. On the edge: imagining ICT and professional legal learning. Web Journal of Current Legal Issues, special issue on Legal Education [Online], edited by Spencer, M. Available at: http://webjcli.ncl.ac.uk/2006/issue3/maharg3.html [Accessed on: 12.2.12]. 
Maharg, P. and Owen, M. 2007. Simulations, learning and the metaverse: changing cultures in legal education, Journal of Information Law \& Technology, 1, [Online]. Available at: http://www2.warwick.ac.uk/fac/soc/law/elj/jilt/2007_1/maharg_owen [Accessed on: 12.4.11].

Maharg, P. 2007 Transforming Legal Education: Learning and Teaching the Law in the Early Twenty-First Century. London: Ashgate Publishing.

Maharg, P. (2013, forthcoming). Beatific moral theory and legal learning. In [title unknown], edited by J. Webb, Rotterdam, Netherlands: Sense Publishers.

Marshall, D. 1984. Adam Smith and the theatricality of moral sentiments. Critical Inquiry, 10(4), 592-613.

Mautner, T. (1993). Francis Hutcheson: Two Texts. Cambridge: Cambridge University Press.

Mill, J. S. (1866). An Examination of Sir William Rowan Hamilton's Philosophy, 2 vols, Boston.

Nardi, B. and O'Day, V.L. 1999. Information Ecologies. Using Technology with Heart. Cambridge, MASS: The MIT Press.

Nelson, R., and Trubek, D. 1992. Arenas of professionalism: the professional ideologies of lawyers in context, in: R. Nelson, D. Trubek \& R. Solomon (Eds) Lawyers' Ideals/Lawyers Practices: Transformations in the American Legal Profession, Ithaca and London, Cornell University Press.

Papadakis, M.A., Loeser, H. and Healy, K. 2004a. Early detection and evaluation of professionalism deficiencies in medical students. Academic Medicine, 76(11), 11006.

Papadakis, M.A., Hodgson, C.S., Teherani, A.P.D. and Kohatsu, N.D. (2004b) Unprofessional behaviour in medical school is associated with subsequent disciplinary action by a state medical board. Academic Medicine, 79(3), 244-79.

Pellegrino, E.D., Veatch, R.M. and Langan, J. eds, 1991. Ethics, Trust and the Professions. Washington DC, Georgetown University Press.

Schneyer, T. 1989. Professionalism as Bar politics: The making of the Model Rules of Professional Conduct. Law \& Social Inquiry, 14(4), 677-736.

Schwarz, M.R. and Wojtczak, A. 2002. Global minimum essential requirements: a road towards competence-oriented medical education. Medical Teacher, 24(2), 125-29.

Sheridan, P. 2007. The metaphysical morality of Francis Hutcheson: a consideration of Hutcheson's critique of moral fitness theory. Sophia, 46(3), 263-75.

Sleeper, R. 1986. The Necessity of Pragmatism. John Dewey's Conception of Philosophy, New Haven: Connecticut and London, Yale University Press.

Smith, A. 1976. The Theory of Moral Sentiments, edited by D.D. Raphael and A.L. Macfie, sixth edition, The Glasgow Edition of the Works and Correspondence of Adam Smith, Oxford: Oxford University Press.

Stronach, I., Corbin, B., McNamara, O., Stark, S. and Warne, T. 2002. Towards an uncertain politics of professionalism: teacher and nurse identities in flux. Journal of Education Policy, 17(1), 109-38.

Stewart, D. 1854. The Collected Works of Dugald Stewart, edited by W. Hamilton, Edinburgh: Constable, two volumes.

Stenhouse, L. 1983. Authority, Education, Emancipation, Heinemann, London.

Stern, D. and Papadakis, M. 2006 The developing physician - becoming a professional. New England Journal of Medicine, 354, 1794-99.

Sullivan, W. 1995. Work and Integrity. The Crisis and Promise of Professionalism in America, second edition, New York: John Wiley \& Sons.

Taylor, T.L. 2006. Play Between Worlds. Exploring Online Game Culture. Cambridge: Massachusetts, MIT Press.

Tanner, L.N. 1997. Dewey's Laboratory School. Lessons for Today. New York \& London: Teacher's College, Columbia University. 
Taverner, D. et al, 2000. Comparison of methods for teaching clinical skills in assessing and managing drug-seeking patients. Medical Education, 34(4), 285-291.

Toddington, S. 1996. The emperor's new skills: The academy, the profession and the idea of legal education. In P.B.H. Birks, ed., What are Law Schools For? Pressing Problems in the Law, vol 2, Oxford University Press, Oxford.

Turco, L. 1999. Sympathy and moral sense: 1725-1740. British Journal for the History of Philosophy, 7(1), 79-101.

Ward, I. 2002. The Echo of a Sentimental Jurisprudence. Law and Critique, 13(2), 107-205.

Webb, J., Nicolson, D. 2005. Public rules and private values: fractured profession(alism)s and institutional ethics. International Journal of the Legal Profession, 12(2), 165-72.

Wolf, F.M. and Turner, E.V. 1989. Congruence between student and instructor perceptions of clinical teaching in paediatrics. Medical Education, 23(2), 161-7.

World Federation For Medical Education Task Force. 2000. Defining international standards in basic medical education. Report of a Working Party, Copenhagen. Medical Education, 34(8), 665-675.

World Health Organization/Education Commission For Foreign Medical Graduates. 1995. Towards a global consensus on quality medical education: serving the needs of population and individuals. Proceedings of the 1994 WHO/ ECFMG Consultation in Geneva, Switzerland. Academic Medicine, 70(7), Suppl. 


\section{Appendix: PEAT 1 Professionalism Learning Outcomes (Law Society of Scotland)}

The full set of learning outcomes for PEAT 1 is available at

http://www.lawscot.org.uk/media/39767/peat_1_guidelines_-_final.pdf.

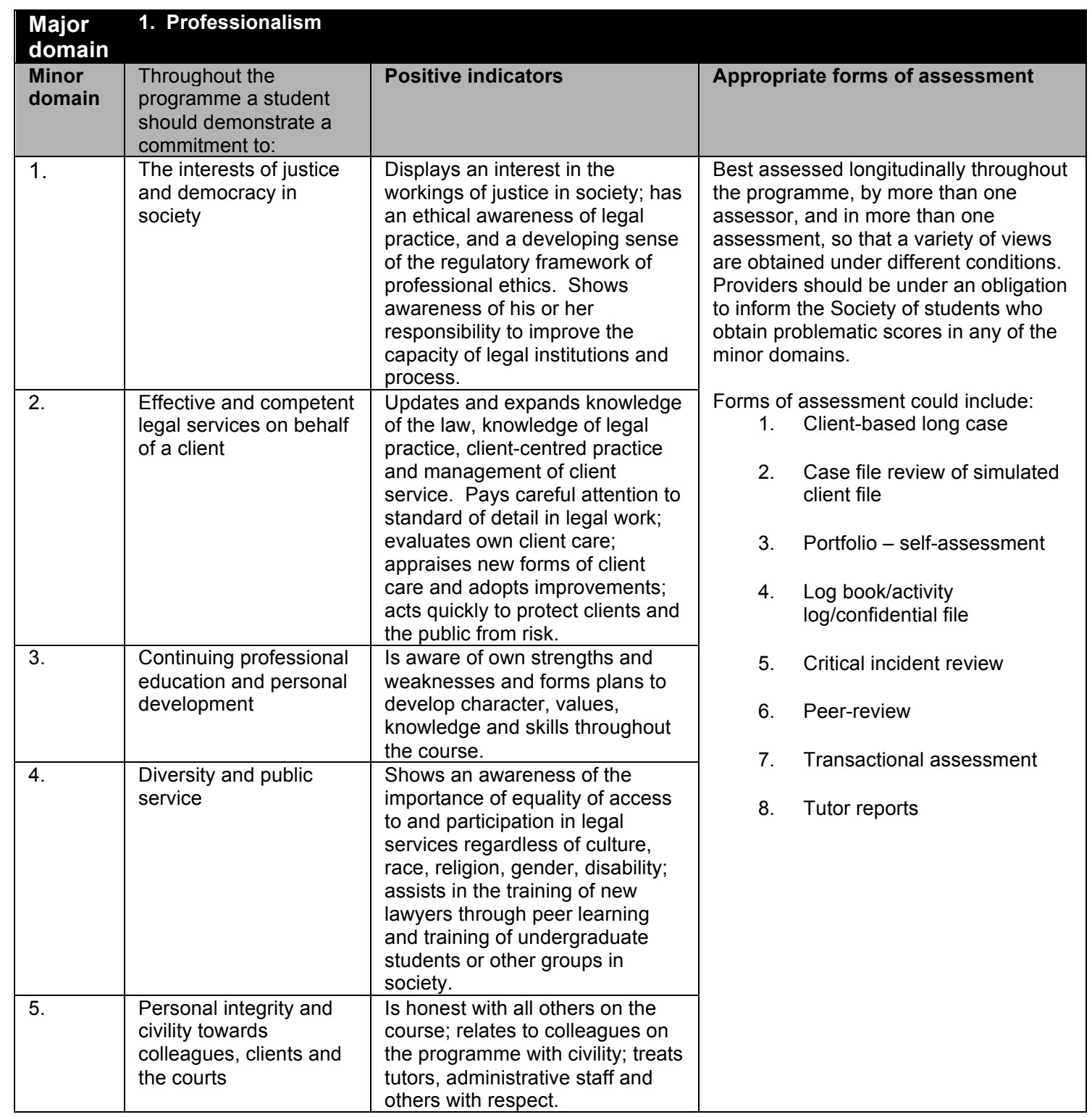

